Natural Hazards and Earth System Sciences (2003) 3: 749-755

(C) European Geosciences Union 2003

Natural Hazards
and Earth
System Sciences

\title{
Surface latent heat flux as an earthquake precursor
}

\author{
S. Dey ${ }^{1}$ and R. P. Singh ${ }^{2}$ \\ ${ }^{1}$ Department of Civil Engineering Indian Institute of Technology Kanpur-208016, India
}

Received: 17 June 2003 - Revised: 23 September 2003 - Accepted: 25 September 2003

\begin{abstract}
The analysis of surface latent heat flux (SLHF) from the epicentral regions of five recent earthquakes that occurred in close proximity to the oceans has been found to show anomalous behavior. The maximum increase of SLHF is found 2-7 days prior to the main earthquake event. This increase is likely due to an ocean-land-atmosphere interaction. The increase of SLHF prior to the main earthquake event is attributed to the increase in infrared thermal (IR) temperature in the epicentral and surrounding region. The anomalous increase in SLHF shows great potential in providing early warning of a disastrous earthquake, provided that there is a better understanding of the background noise due to the tides and monsoon in surface latent heat flux. Efforts have been made to understand the level of background noise in the epicentral regions of the five earthquakes considered in the present paper. A comparison of SLHF from the epicentral regions over the coastal earthquakes and the earthquakes that occurred far away from the coast has been made and it has been found that the anomalous behavior of SLHF prior to the main earthquake event is only associated with the coastal earthquakes.
\end{abstract}

\section{Introduction}

The recent Gujarat earthquake of 26 January 2001 has shown significant changes on the land (surface and subsurface) (Singh et al., 2001a, b) and in ocean parameters (Singh et al., 2001c, 2002). The significant changes in ocean parameters associated with earthquakes occurring near the ocean have prompted us to study the changes in land and atmospheric parameters associated with these earthquakes. The analysis of multi-sensors data has shown anomalous behavior of water vapor in the atmosphere prior to the Gujarat and other earthquakes, especially those that occurred near the ocean with focal depth up to $33 \mathrm{~km}$ (Dey et al., 2003).

Correspondence to: R. P. Singh

(ramesh@iitk.ac.in)
Although earthquake prediction is still a challenging task, recent studies have shown that numerous geophysical parameters are closely associated with the earthquakes (Knopoff, 1996). Numerous precursory geophysical and ionospheric parameters have been found to be associated with earthquakes that occurred throughout the globe (Hayakawa and Fujinawa, 1994; Merzer and Klemperer, 1997; Hayakawa, 1999; Biagi et al., 2001a, b; Molchanov et al., 2001; Ohta et al., 2001; Uyeda et al., 2001). These parameters can prove to be potential precursors of an earthquake if we understand their characteristic behavior. In the last few years, many disastrous earthquakes have occurred frequently near the ocean (http://earthquake.usgs.gov/activity/world.html). In the present paper, we have considered five such earthquakes, with a magnitude $>5$ (Table 1), having similar characteristics in view of their focal depth (within crustal depth) and proximity to the oceans. In this paper, we have analyzed the SLHF behavior over the epicentral regions of coastal earthquakes and earthquakes that occurred far away from coast, to study the SLHF behavior both prior and after the earthquakes.

\section{SLHF}

SLHF is the heat released by phase changes due to solidification or evaporation or melting. The energy transport between the Earth, ocean and atmosphere through the evaporation at the surface-atmosphere interface partly compensates for energy losses due to radiation processes in the atmosphere (Schulz et al., 1997). The SLHF is highly dependent on meteorological parameters, such as relative humidity, wind speed, ocean depth and proximity from the ocean. The energy loss at the surface through simultaneous exchange of water vapor and heat with the atmosphere is higher at the ocean surface compared to those over the land; hence, SLHF is higher at the ocean surface and a sharp contrast is always observed at the ocean-land interface. SLHF has been found 
Table 1. Details of the earthquakes

\begin{tabular}{|c|c|c|c|c|c|c|}
\hline Place & Date & Epicenter & Magnitude & $\begin{array}{l}\text { Focal Depth } \\
\qquad(\mathrm{km})\end{array}$ & $\begin{array}{l}\text { Background } \\
\text { Noise }(\mu+1.5 \sigma)\end{array}$ & $\begin{array}{l}\text { Average distance } \\
\text { from ocean }(\mathrm{km})\end{array}$ \\
\hline $\begin{array}{l}\text { Gujarat, } \\
\text { India (1) }\end{array}$ & 26 Jan 2001 & $70.32 \mathrm{E}, 23.33 \mathrm{~N}$ & 7.8 & 23.6 & $\begin{array}{l}1.53(\mathrm{Jan}) \\
2.16(\mathrm{Feb})\end{array}$ & $70-80$ \\
\hline $\begin{array}{l}\text { Andaman, } \\
\text { India (2) }\end{array}$ & 14 Sep 2002 & $93.11 \mathrm{E}, 13.09 \mathrm{~N}$ & 6.5 & 33 & $\begin{array}{l}1.88 \text { (Sep) } \\
1.25 \text { (Oct) }\end{array}$ & 0 \\
\hline $\begin{array}{l}\text { Pondichery, } \\
\text { India (3) }\end{array}$ & 25 Sep 2001 & $80.23 \mathrm{E}, 11.95 \mathrm{~N}$ & 5.4 & 19 & $\begin{array}{l}1.21 \text { (Sep) } \\
1.97 \text { (Oct) }\end{array}$ & $0-5$ \\
\hline $\begin{array}{l}\text { Latur, } \\
\text { India (4) }\end{array}$ & 30 Sep 1993 & $76.45 \mathrm{E}, 18.07 \mathrm{~N}$ & 6.3 & 10 & $\begin{array}{l}0.32 \text { (Sep) } \\
0.34 \text { (Oct) }\end{array}$ & $300-350$ \\
\hline $\begin{array}{l}\text { Jabalpur, } \\
\text { India (5) }\end{array}$ & 22 May 1997 & $80.04 \mathrm{E}, 23.08 \mathrm{~N}$ & 6 & 35 & $\begin{array}{l}1.55 \text { (May } \\
\text { and June) }\end{array}$ & $750-800$ \\
\hline Taiwan (6) & 20 Sep 1999 & $120.98 \mathrm{E}, 23.72 \mathrm{~N}$ & 7.7 & 33 & $\begin{array}{l}1.42(\mathrm{Sep}) \\
2.57(\mathrm{Oct})\end{array}$ & $0-5$ \\
\hline Mexico (7) & 22 Jan 2003 & $103.89 \mathrm{~W}, 18.81 \mathrm{~N}$ & 7.3 & 33 & $\begin{array}{l}1.65(\mathrm{Jan}) \\
2.3(\mathrm{Feb})\end{array}$ & $5-10$ \\
\hline
\end{tabular}

to decrease away from the land-ocean interface towards the land.

Prior to an earthquake, the accumulation of stress results in the thermal infrared emission (Freund and Ouzounov, 2001), which enhances the rate of energy exchange between surface and atmosphere, resulting in increase of SLHF. The SLHF can be retrieved accurately from satellite data (Schulz et al., 1997; Singh et al., 2001d), which provides an opportunity for long-term monitoring of the parameter, in order to develop future precursor models. Variations in SLHF are also controlled by the changes in surface temperature (ST), which is believed to be a precursor parameter during an earthquake (Tronin, 2000). The ST anomaly based on thermal infrared satellite data as a precursor has been found during earthquakes in China (10 January 1998) and Kobe (Japan) on 17 January 1995 (Tronin et al., 2002).

\section{Data used}

The SLHF data of five earthquakes have been taken over the pixel covering the epicenter of the earthquakes from the National Center for Environmental Prediction (NCEP) (http://iridl.ldeo.columbia.edu/). The details of these earthquakes are given in Table 1, which have been taken from USGS (http://earthquake.usgs.gov/activity/world.html). Table 1 gives information about the epicenters of these earthquakes and focal depths. Figure 1 shows the epicenter location of earthquakes considered in the present study. We have considered coastal earthquakes that occurred in India, Taiwan and Mexico and also considered two Indian earthquakes that occurred far away from the coast. The ap- proximate distance of the ocean from the location of the epicenter of the earthquakes is given in Table 1. The data has been downloaded from the Scientific Computing Division of the National Center for Atmospheric Research (NCAR) (http://ingrid.ldeo.columbia.edu/SOURCES/ NOAA/NCEP-NCAR/). The data set is represented by the Gaussian grid of 94 lines from equator to pole, with a regular $1.8^{\circ}$ longitudinal spacing and projected into $2^{\circ}$ latitude by $2^{\circ}$ longitude in a rectangular grid. The spatial distribution of the SLHF anomaly prior to the main event has been studied in a $12^{\circ}$ by $12^{\circ}$ area $\left(\sim 1774224 \mathrm{~km}^{2}\right)$, with the pixel covering epicenter of the earthquakes at the center. The global database of various meteorological and surfacial parameters is maintained at NCEP. This database is generated by taking into consideration the measured values at various worldwide stations and also retrieved from satellite data. The fluxes used in the operational weather forecast models incorporate in-situ observations through an assimilation process. The main drawback of the data source is the frequent change in assimilation methodology and in model resolution, which has been solved by the re-analysis procedure by NCEP, incorporating the whole archived data set into a single frozen data assimilation system. The validation and detailed description of the reanalysis of the NCEP SLHF data have been discussed by Kalnay et al. (1996). The daily values of SLHF have been considered for a two months period prior to and after the earthquakes. The mean value during that period has been considered in order to take into account care of the seasonal effect. The monthly mean has been subtracted from the daily values to study the anomalous behavior ( $\triangle \mathrm{SLHF})$ of SLHF during the earthquakes.

For the normalization of SLHF, we have divided the daily 
$60 \mathrm{E}, 40 \mathrm{~N}$

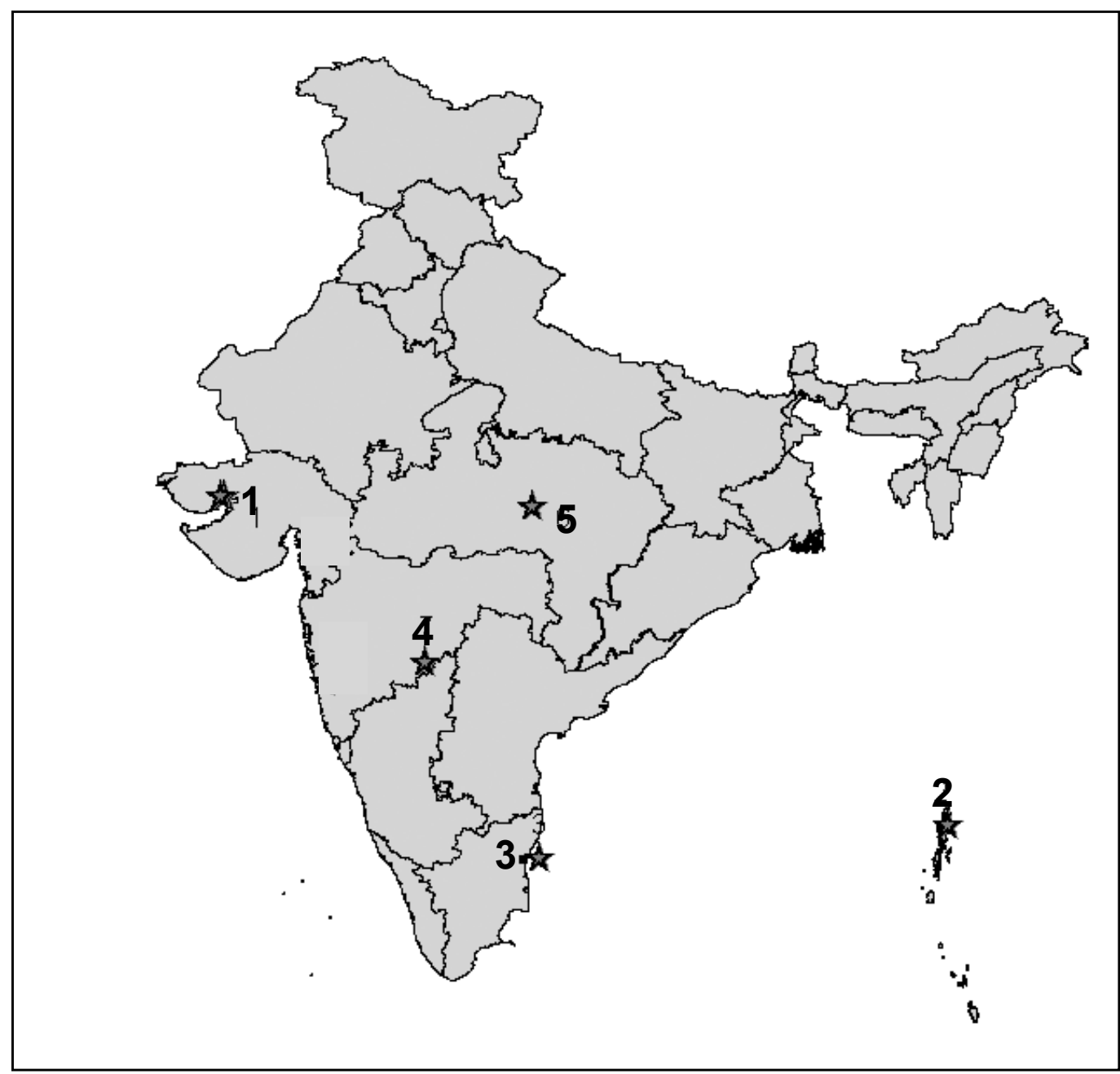

$100 \mathrm{E}, 0 \mathrm{~N}$

Fig. 1. Locations of the epicenters of the earthquakes.

SLHF value by the standard deviation $(\sigma)$ of the SLHF data for that day considering a 10 -years data set. The maximum values of SLHF depend on month to month, season to season and location to location, and it is affected by the winds, tides and monsoon. For each earthquake location, the mean $(\mu)$ value of SLHF plus 1.5 times the standard deviation of SLHF have been taken as background noise.

\section{Results and discussion}

Table 1 shows details of five earthquakes, which are closely lying near the oceans (Fig. 1). The distance of the epicenters of these earthquakes from the ocean is quite variable, approximate distance from the epicenter to the ocean is given in Table 1. Variations of normalized SLHF are shown in Fig. 2. In each figure the horizontal broken line shows the maximum normalized $\triangle \mathrm{SLHF}$ values, which is considered as the maximum background noise daily mean of 10 years plus 1.5 times standard deviation. The maximum background noise for each earthquake is shown in Table 1. This background noise varies with location to location and month to month. The solid bars show the day of the main earthquake event. The behavior of normalized $\triangle$ SLHF in the epicentral region shows a similar trend for all the five earthquakes (Table 1). Variations in the $\triangle$ SLHF values during the month of the main earthquake events are found to be similar in the nonearthquake years, whereas in all five cases the standard deviations of the data set are found to be higher in the earthquake year. The maximum increase in normalized $\triangle$ SLHF has been observed 2-7 days prior to the main earthquake event. Prior to the main earthquake event, normalized $\triangle$ SLHF is found to be greater than the sum of the mean SLHF plus 1.5 times the standard deviations, which indicates that only before an earthquake does the normalized $\triangle$ SLHF value become significantly high. All the normalized $\triangle$ SLHF values are found 


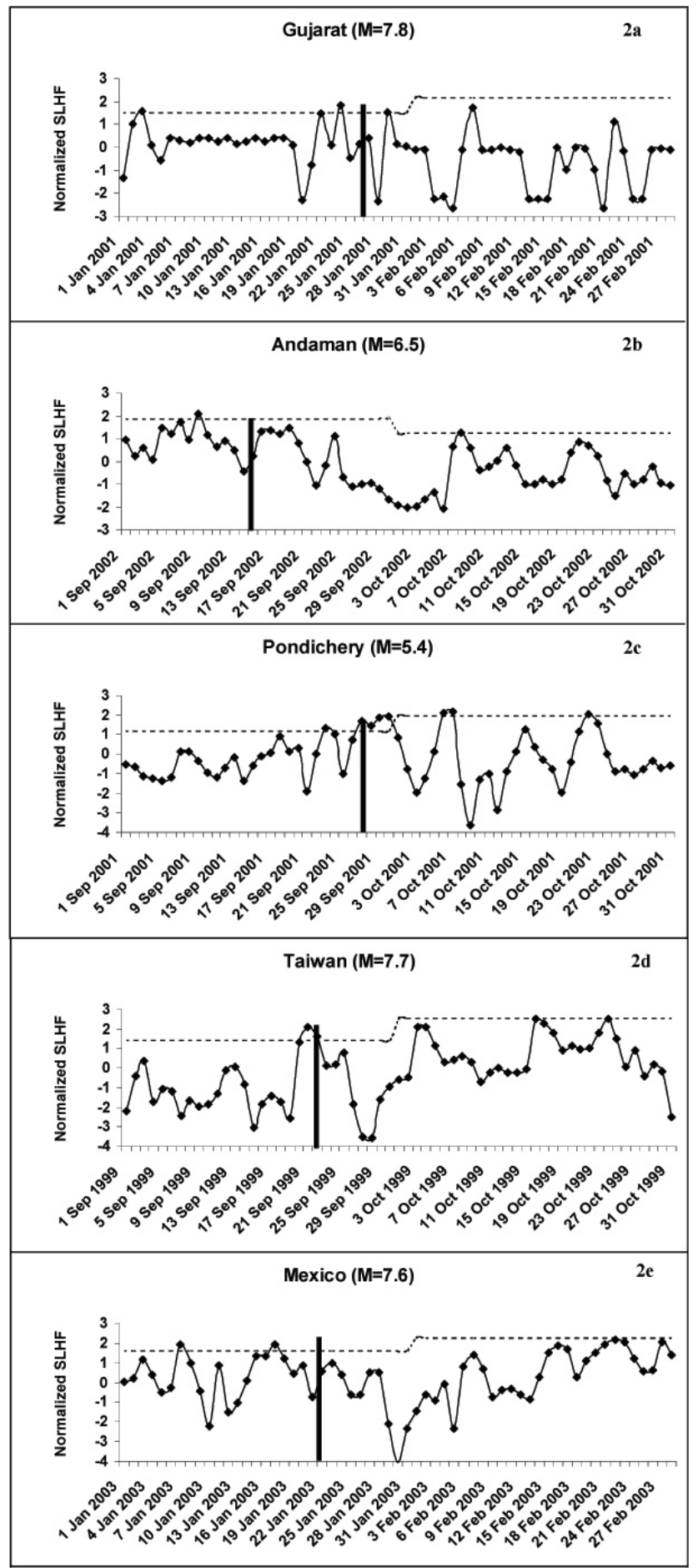

Fig. 2. Normalized SLHF anomaly at the epicenters of (a) Gujarat, (b) Andaman, (c) Pondichery, (d) Taiwan and (e) Mexico earthquakes.

to lie within this range and, therefore, it is considered as background noise, but prior to the main earthquake events in all five locations, the normalized $\triangle$ SLHF values are found to be higher than the maximum range of background noise. The normalized $\triangle \mathrm{SLHF}$ is found to increase from the back-

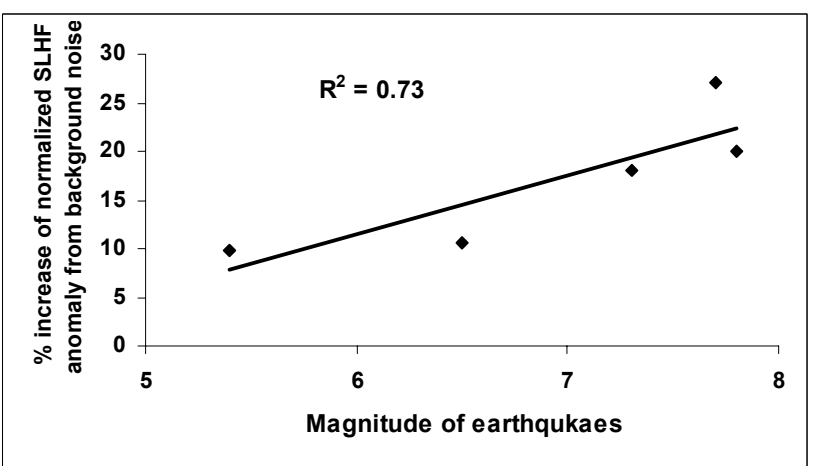

Fig. 3. The relation between the increase (in \%) between the normalized $\triangle$ SLHF anomaly values and the magnitude of the earthquakes.

ground noise by $20 \%, 2$ days prior to the earthquake in $\mathrm{Gu}-$ jarat (Fig. 2a); by $10.6 \%, 5$ days prior to the earthquake in Andaman (Fig. 2b); 9.9\%, 2 days prior to the earthquake in Pondichery (Fig. 2c); 27\%, 1 day prior to the earthquake in Taiwan (Fig. 2d) and 18\%, 5 days prior to the earthquake in Mexico (Fig. 2e). The percentage increase in the normalized SLHF value prior to the main earthquake event is found to show good correlation $\left(\mathrm{R}^{2}=0.73\right)$ with the magnitude of the earthquakes (Fig. 3). After the main earthquake event, the normalized $\triangle$ SLHF has been found to decrease and after some days then increase, before it acquires the average background value. Figure 4 shows the spatial distribution of the SLHF values in the Gujarat region prior to the earthquake. Normally the SLHF shows a moderate contrast between the ocean and the land since SLHF over the Arabian ocean is less than $35 \mathrm{~W} / \mathrm{m}^{2}$ in the month of January and the SLHF over the adjacent land is approximately less than $0 \mathrm{~W} / \mathrm{m}^{2}$. The SLHF contrast increases significantly prior to the earthquake (dark color is seen over the Gujarat region and also over the ocean on 25 and 26 January). The strong SLHF contrast (dark solid circular color) is seen over the southeast on 22 January 2001 is found to be associated with the tectonically active zones. The migration of the SLHF contrast seems to begin from this zone towards the epicentral region over the land and adjacent ocean regions. This migration of strong SLHF contrast zone over the ocean and in the epicentral region is likely to be due to heat conduction through water and also through fluid present in the pore space of rocks and soils. Since the heat conduction is faster and effective in ocean water, the SLHF contrast seems to spread over the Arabian ocean faster, whereas the SLHF contrast seen over the land area is smaller compared to the oceanic region because of the lower heat conduction through pore fluids in the rocks and soils. The strong SLHF contrast is seen over the epicentral region on 24 January, i.e. 2 days prior to the main earthquake event of 26 January; soon after the earthquake this strong SLHF contrast is found to disappear (Fig. 4).

We have studied the behavior of SLHF for other intraplate earthquakes occurring away from the ocean. Figures $5 \mathrm{a}$ and 


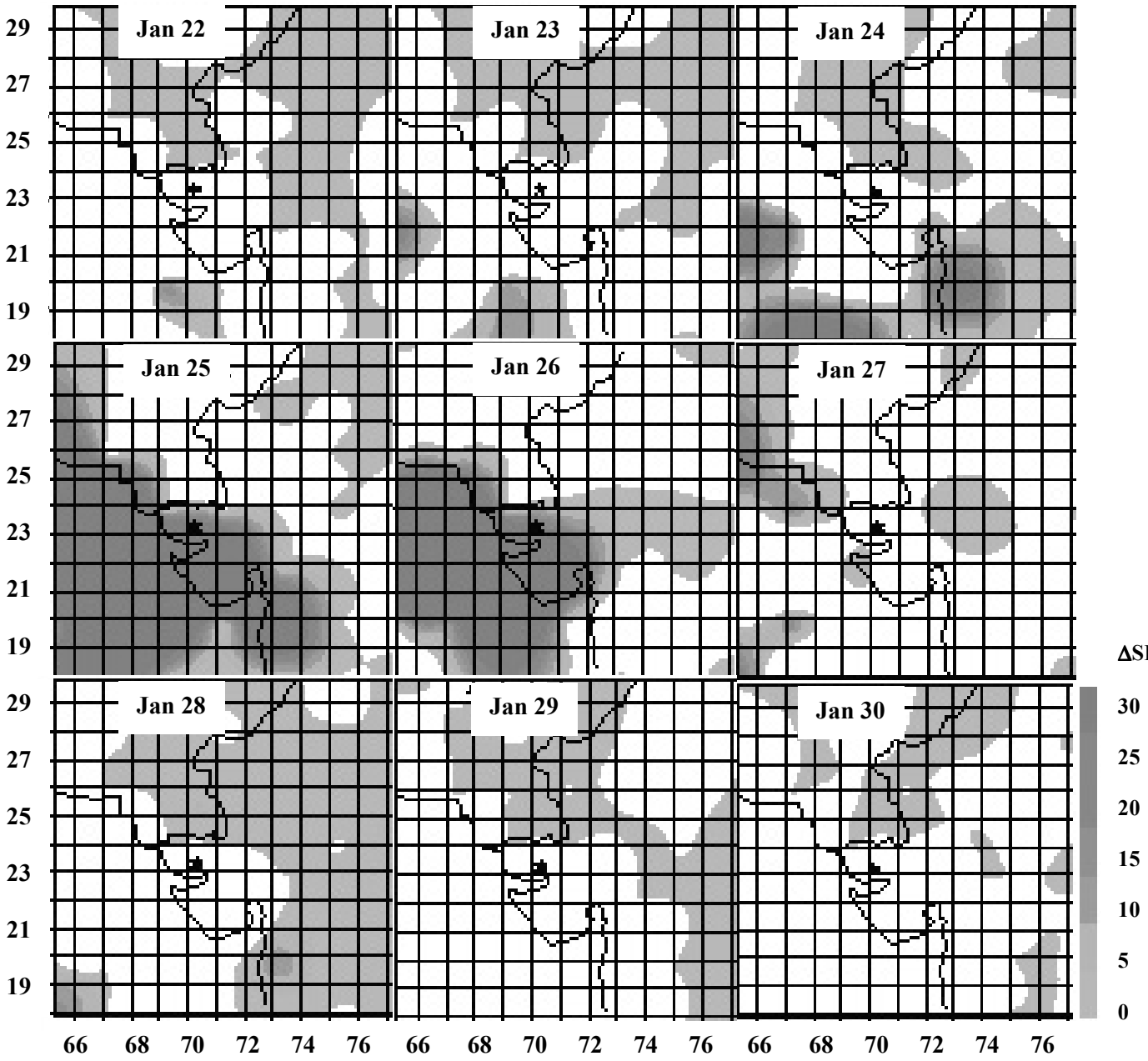

Fig. 4. Spatial distribution of SLHF anomaly in the Gujarat region.

$5 \mathrm{~b}$ show the normalized SLHF for the Latur and Jabalpur earthquakes in India (maximum background noise shown as broken line and the values are given in Table 1), where no such SLHF behavior is found prior to the earthquake. However, after the main earthquake event the SLHF anomaly seems to show higher values in the case of the Latur and Jabalpur earthquakes. This clearly shows that the earthquakes occurring far away from the ocean takes a while; as a result, the strong SLHF anomaly seen prior to the coastal earthquakes shows a long delay in displaying a strong SLHF anomaly, as a result of the strong interaction between the ocean-land-atmosphere (Figs. 5a and b).

The magnitude of the changes in the normalized SLHF associated with these five earthquakes are likely to be associated with the prevailing meteorological parameters in the earthquake regions, location of earthquakes, proximity of the epicenter to the ocean, season in which the earthquake occurred and the coupling between the land-ocean-atmosphere. The nature of such a coupling and the hidden physical processes is yet to be explored. The increase in infrared thermal (IR) temperature (http://amesnews.arc.nasa.gov) over the epicentral region prior to the earthquake leads to intense land-ocean-atmosphere interaction giving anomalous SLHF prior to the earthquake. The accumulation of stress prior to the earthquake in the epicentral region is likely to be responsible for the increase in IR temperature prior to the earthquake. The manifestation of the stress accumulation in terms of surface temperature and SLHF is prominent in the case of shallow focal depth earthquakes. The change in SLHF is likely to be attributed to a dis-equilibrium in the mineralogical phase transformation due to the accumulation of stress (Bina, 1998). This effect is less prominent in the case of shallow-focus earthquakes. The SLHF is enhanced by the interaction of ocean and atmosphere in larger regions which is very much dependent on the proximity of the earthquake epicenters to the ocean in controlling the variations of SLHF. The maximum increase in SLHF 2-7 days prior to the earthquake is likely to be due to the role of fluid within the Earth's crust (Tronin et al., 2002) and the increased interaction between the atmosphere, ocean and land. This interaction is likely to be governed by numerous parameters prevailing in the earthquake epicenters and surrounding regions. The SLHF shows the exchange of water vapor in the atmosphere. Anomalous concentration of water vapor in the atmosphere 


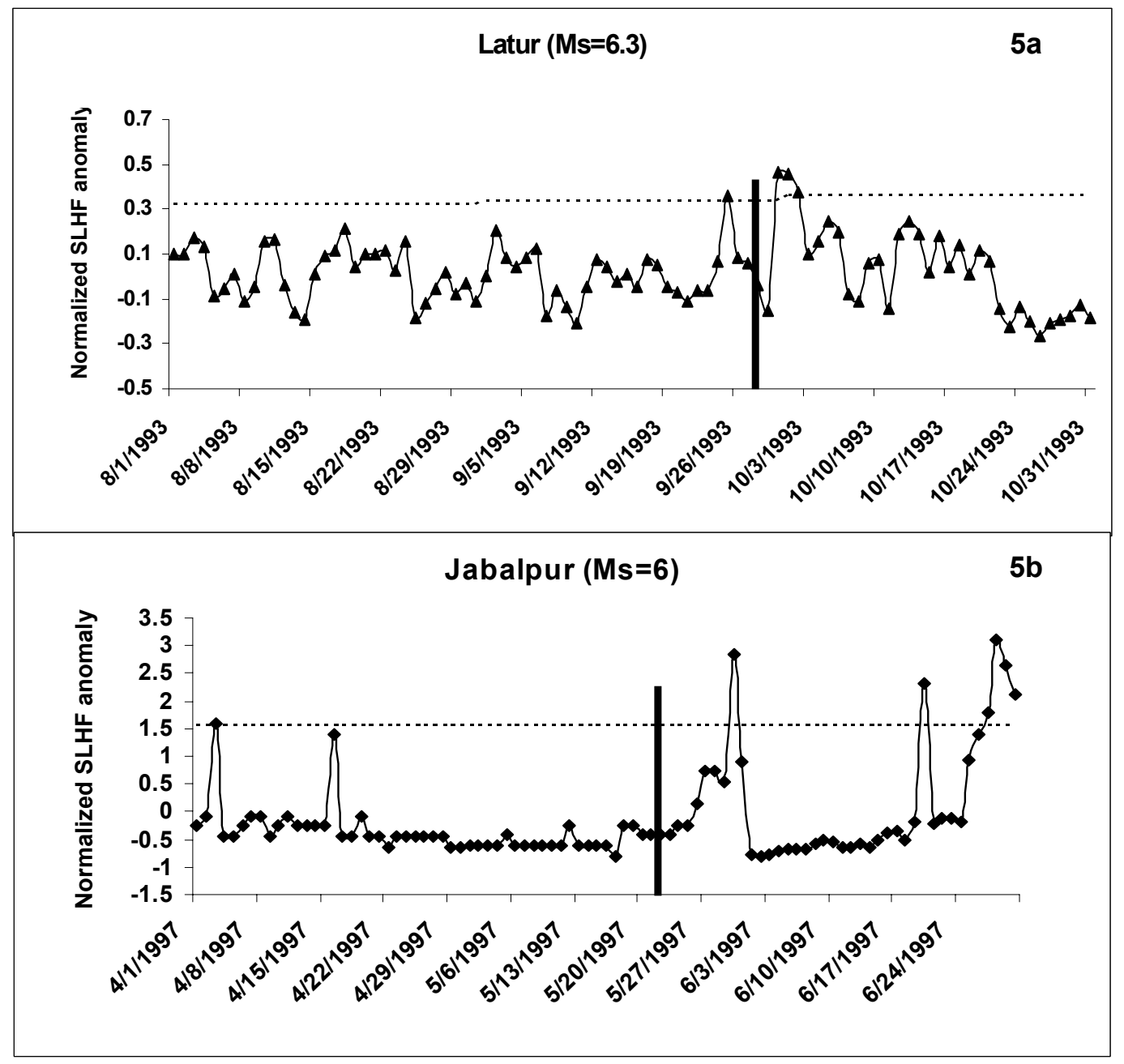

Fig. 5. Normalized SLHF anomaly at the epicenters of (a) Latur and (b) Jabalpur earthquake.

has been observed in the Gujarat region prior to the earthquake (Dey et al., 2003), which supports the idea of a landocean-atmosphere interaction during the earthquake. Water vapor is an optically active greenhouse gas, which absorbs a part of the Earth's outgoing infrared radiation and contributes to the accumulation of heat near the surface (Tronin et al., 2002). The accumulated heat affects the energy exchange; as a result, an increase in SLHF prior to the earthquake is found. After the main earthquake event, the release of accumulated stress shows an immediate decrease in SLHF. The higher moisture content in the soil and humidity in the air facilitates the energy transfer to the atmosphere.

\section{Conclusion}

The analysis of SLHF data of the recent five earthquakes has shown anomalous behavior prior to the earthquakes. Such anomalous behavior is only found to be associated with earthquakes that occurred in the close proximity to the ocean. The systematic pattern of SLHF shows a potential precur- sor to provide information about disastrous earthquakes occurring near coastal regions well in advance. The highresolution remote sensing data with better spatial and temporal resolutions may provide more reliable information about SLHF, which can be easily used, for early warning of coastal earthquakes.

Acknowledgements. The surface latent heat flux data has been downloaded from NCEP site (http://iridl.ldeo.columbia.edu). The authors are grateful to Mr. V. P. Singh for his help in generating Fig. 4. The authors are grateful to two anonymous reviewers for their comments.

\section{References}

Biagi, O., Piccolo, R., Ermini, A., et al.: Hydrogeochemical precursors of strong earthquakes in Khamchatka: further analysis, Natural Hazards and Earth System Sciences, 1, 9-14, 2001a.

Biagi, O., Piccolo, R., Ermini, A., et al.: Possible earthquake precursors revealed by LF radio signals, Natural Hazards and Earth System Sciences, 1, 99-104, 2001b. 
Bina, C. R.: A note on latent heat release from disequilibrium phase transformations and deep seismogenesis, Earth Planets Space, 50, 1029-1034, 1998.

Dey, S., Sarkar, S., and Singh, R. P.: Anomalous changes in column water vapor after Gujarat earthquake, Adv. Space R. (in press), 2004.

Freund, F. and Ouzounov, D.: EOS Trans. AGU, Fall Meet. Suppl. Abstract, 82(47), 2001.

Hayakawa, M. and Fujinawa, Y.: Electromagnetic Phenomena Related to earthquake Prediction, Terra Sci. Publ. Comp. Tokyo, p. 677, 1994.

Hayakawa, M.: Atmospheric and Ionospheric Electromagnetic Phenomena Associated with Earthquakes, Terra Sci., Publ. Comp., Tokyo, p. 995, 1999.

Kalnay, E., Kanamitsu, M., Kistler, R., et al.: Bull. Am. Meteorol. Soc., 77 (3), 437-471, 1996.

Knopoff, L.: Earthquake prediction: The scientific challenge, Proceeding of National Science, USA, 93, 3719-3720, 1996.

Merzer, M. and Klemperer, S. L.: Modeling low-frequency magnetic field precursors to the Loma Prieta earthquake with a precursory increase in fault-zone conductivity, Pur. A. Geoph., 150, 217-248, 1997.

Molchanov, O., Kulchitsky, A. and Hayakawa, M.: Inductive seismo-electromagnetic effect in relation to seismogenic ULF emission, Natural Hazards and Earth System Sciences, 1, 61-68, 2001.

Ohta, K., Ummeda, K., Watnabe, N., and Hayakawa, M.: ULF/ELF emissions observed in Japan, possibly associated with the ChiChi earthquakes in Taiwan, Natural Hazards and Earth System Sciences, 1, 37-42, 2001.
Schulz, J., Meywerk, J., Ewald, S., and Schlussel, P.: Evaluation of satellite-derived Latent Heat Fluxes, J. Climate, 10 (11), 27822795, 1997.

Singh, R. P., Sahoo, A. K., Bhoi, S., Kumar, M. G., and Bhuiyan, C. S.: Ground deformation of Gujarat earthquake of 26 January 2001, Journal of Geological Society of India, 58, 209-214, 2001a.

Singh, R. P., Bhoi, S., Sahoo, A. K., Raj, U., and Ravindran, S.: Surface manifestations after the Gujarat earthquake, Current Science, 81 (2), 164-166, $2001 \mathrm{~b}$.

Singh, R. P., Bhoi, S., and Sahoo, A. K.: Significant changes in the ocean parameters after the Gujarat earthquake, Current Science, 80 (11), 1376-1377, 2001c.

Singh, R., Simon, B., and Joshi, P. C.: Estimation of surface latent heat fluxes from IRSP4/ MSMR satellite data, Proc. Indian Acad. Sci. (Earth Planet Science), 110 (3), 231-238, 2001d.

Singh, R. P., Bhoi, S., and Sahoo, A. K.: Changes observed on land and ocean after Gujarat earthquake 26 January 2001 using IRS data, Int. J. Remot., 23 (16), 3123-3128, 2002.

Tronin, A. A.: Thermal IR satellite sensor data application for earthquake research in China, Int. J. Remot., 21 (16), 3169-3177, 2000.

Tronin, A. A., Hayakawa, M., and Molchanov, O. A.: Thermal IR satellite data for earthquake research in Japan and China, J. Geodyn., 33, 519-534, 2002.

Uyeda, S., Nagao, T., Hattori, K., et al.: Geophysical observatory in Kamchatka region for monitoring of phenomena connected with seismic activity, Natural Hazards and Earth System Sciences, 1, 3-7, 2001. 